\title{
Analysis of factors influencing hospital- acquired infection in postoperative patients with intracranial aneurysm
}

\author{
Jun Wang ${ }^{1}$, Yuanyuan $\mathrm{Ji}^{1}$, Lidan Jiang ${ }^{1}$, Xia Zhao ${ }^{2}$, Shaochen Guan ${ }^{3}$, Piao Yang ${ }^{1}$, Jie Yu' ${ }^{1}$ Yunyun Liu ${ }^{1}$ and \\ Hongqi Zhang ${ }^{1 *}$
}

\begin{abstract}
Background: Hospital-acquired infection (HAl) is a serious complication of neurosurgery. In recent years, the medical body has paid increasing attention to this issue.

Aim: We investigated the status of HAls in patients who had undergone surgery for intracranial aneurysms and analysed their risk factors.

Methods: A retrospective analysis was carried out on the medical records of 542 patients with intracranial aneurysms after they were admitted for neurosurgery at Xuanwu Hospital of Capital Medical University between January and December 2016. Cases studied were divided into an infection group and a control group. Logistic regression analysis of the data was carried out.
\end{abstract}

Findings: Of the 542 patients with intracranial aneurysms who underwent surgery, 77 HAls occurred in 64 patients, with an infection prevalence of $11.8 \%$ and prevalence of infection cases of $14.2 \%$. Logistic regression showed that an admission Glasgow Coma Scale (GCS) score of less than 8 points (odds ratio $=4.261,95 \%$ confidence interval 1.102-16.476), hyperglycaemia $(2.759,1.159-6.564)$, hypothermia treatment $(6.557,2.244-19.159)$, and central venous catheterisation (CVC) $(8.853,2.860-27.398)$ were independent risk factors for HAls in patients with intracranial aneurysm who underwent surgery.

Conclusion: Being comatose upon hospital admission, having hyperglycaemia or hypothermia, and indwelling CVC are major risk factors for HAls in patients undergoing surgery for intracranial aneurysms.

Keywords: Intracranial aneurysm, Hospital-acquired infection, Risk factor, Case-control study

\section{Introduction}

An intracranial aneurysm is a bulged, weakened area in the wall of an artery in the brain. Surgical intervention before aneurysm rupture is the main method used to reduce the risk of bleeding and mortality, however surgical and surgery-related factors increase the risk of HAI [1]. Patients with ruptured intracranial aneurysms often have severe illness, spend a long time hospitalized and being bedridden, and experience complications such as trouble of consciousness and other neurological impairments.

\footnotetext{
* Correspondence: xwzhanghq@163.com

${ }^{1}$ Department of Neurosurgery, Xuanwu Hospital, Capital Medical University, China International Neuroscience Institute (China-INI), 45 Changchun Street, Beijing 100053, China

Full list of author information is available at the end of the article
}

After craniotomy, patients are more prone to HAI as a consequence of the length and difficulty of this operation. HAI can aggravate the patient's condition, seriously interfere with clinical treatment, prolong the patient's hospitalization time, increase their treatment costs and re-admission rate within 30 days, and lead to severe disability and death. Thus, it causes medical disturbances and increases the economic burden on society and individuals $[2,3]$.

Prevention and control of infection is the cornerstone of patient safety procedures, and HAI is a serious threat to patient safety [4]. A large number of studies have confirmed that interventions using evidence-based strategies can prevent the occurrence of HAI [5]. Accurate identification of the risk factors associated with HAI and early 
prevention and control play important parts in reducing its incidence. In recent years, investigations and analyses have been conducted in various fields, from various perspectives, to determine the factors affecting HAI and to develop interventions. Amey et al [6] analysed the risk factors for respiratory infection in 103 patients with aneurysmal subarachnoid haemorrhage clipping. Postoperative tracheal intubation of more than $48 \mathrm{~h}$, tracheotomy, and stay in the intensive care unit (ICU) of more than 5 days were independent risk factors for respiratory infection. Frontera et al. [7] and Cinotti et al. [8], and others found that the risk factors for HAI in patients with subarachnoid haemorrhage included age, sex, poor clinical condition upon hospital admission, ICU admission, oral intubation, tracheotomy, and urethral/ventricular drainage. Various risk factors for infection have been identified in different research populations. A few studies on HAI in patients with intracranial aneurysms have been conducted. The epidemiological and risk factors for nosocomial infection in patients with intracranial aneurysms need to be further explored.

In addition, previous studies on risk factors and interventions for HAI have mainly focused on the role of doctors; only few studies have considered the perspective of nurses. Nursing staff represent the clinical front line in terms of staff contact with patients, and they have an indispensable part to play in hospital infection control [9-11]. For that reason, this study considers HAI from the perspective of the nursing staff. The research objectives are as follows: to describe the epidemiology of HAI in patients with intracranial aneurysms; to determine the risk factors associated with HAI in patients with intracranial aneurysms; and to analyse the relationship between HAI and patient prognosis.

\section{Methods}

\section{Subjects}

Patients who were admitted to the Department of Neurosurgery, Xuanwu Hospital of Capital Medical University, between the 1st of January and the 31st of December 2016, were selected according to the following criteria. Inclusion criteria: patients diagnosed with intracranial aneurysms by neurosurgical physicians combined with clinical signs and symptoms, imaging data, and laboratory data; patients undergoing surgery and intervention during hospitalization. Exclusion criteria: patients who had been diagnosed or were in latent infection before admission. Elimination criteria: patients who were missing more than $10 \%$ of their medical records. Participants were divided into an infection group $(n=64)$ and a control group $(n=478)$. The control group had patients without hospital-acquired infections. This study was approved by the Xuanwu Hospital Ethics Review Committee (Clinical Research Council [2017]024).

\section{Method}

This was a retrospective case-control study. According to the selection criteria, the retrospective medical information survey method $[12,13]$ was used to collect patient medical data using a self-designed form, which included the patient's basic information, diagnosis and treatment data, disease-related symptoms and signs, as well as test and imaging results. Basic data (age, gender, diagnosis, history, etc.), laboratory data (leucocyte, albumin, blood glucose, liver function, renal function, electrolytes, etc.), and treatment information (length of stay in ICU, mechanical ventilation, surgery, postoperative blood transfusion, hypothermia treatment, central venous catheterization, etc.) were collected. Outcome at discharge was assessed by the Glasgow Outcome Score (GOS).

\section{Diagnostic criteria}

The diagnostic criteria were based on the Diagnostic Standards for Hospital Acquired Infections (Trial) issued by the Ministry of Health of the People's Republic of China on 3 January 2001 to define the criteria for diagnosis of HAI [14]. This study included diagnoses of hospital infections involving the respiratory system, blood system, central nervous system, and urinary system.

\section{Statistical analysis}

EpiData 3.0 was used for data entry and system logic error detection. Statistical analysis was performed using SPSS 22.0. The count data is presented as frequency (percentage) and the differences between groups were assessed using the $x^{2}$ test. The normally distributed continuous data is presented as mean \pm standard deviation, and the non-normally distributed continuous data is presented as median (P25, P75). When the data was normally distributed and the between-group variance was equal, differences between groups were assessed using $t$ tests; the rank sum test was used when the data showed a biased distribution. Univariate analysis was used to perform preliminary variable selection, using an $\alpha$ level of 0.1. On the other hand, logistic stepwise regression analysis was used to analyse the independent predictors of HAI in patients with intracranial aneurysms; differences with $P<0.05$ were considered statistically significant.

\section{Results}

\section{Occurrence of $\mathrm{HAI}$}

A total of 542 patients with neurosurgical intracranial aneurysms were enrolled, including 225 males (41.5\%) and 317 females (58.5\%), aged 18-83 years, with an average age of $54.5 \pm 11.8$ years. A total of 77 cases of hospital infections occurred in 64 patients, with an infection rate of $11.8 \%$ and an infection case rate of $14.2 \%$. The most common type was respiratory infections, with 49 
cases $(63.6 \%)$, followed by infections involving the blood system (16 cases, 20.8\%), central nervous system (10 cases, $13.0 \%$ ), and urinary system (only two cases, $2.6 \%$ ) (Table 1). Hospital infections occurred 1 to 18 days after surgery, with an average occurrence of 5 days after surgery.

\section{Univariate analysis of $\mathrm{HAI}$}

Univariate analysis indicated that lower activities of daily living score on admission, emergency admission, mechanical ventilation, taking antiplatelet aggregation drugs, admission GCS score of less than 8 points, high HuntHess grade on admission, albumin reduction, hyperglycaemia, hyponatremia, surgical procedure, unexpected reoperation, operation time $>4 \mathrm{~h}$, non-class $\mathrm{I}$ incision, intraoperative blood loss, hypothermia therapy, and central venous catheterization were factors associated with HAI in patients with intracranial aneurysm surgery $(P<$ 0.05) (Table 2).

\section{Multivariate analysis of $\mathrm{HAI}$}

Multivariate analysis was performed for the variables for which $P<0.1$ in the univariate analysis. From the logistic regression results, it appeared that admission GCS score $\leq 8$ points (odds ratio $=4.261,95 \%$ confidence interval 1.102-16.476), hyperglycaemia (2.759, 1.1596.564), hypothermia treatment (6.557, 2.244-19.159), and CVC (8.853, 2.860-27.398) were independent risk factors for HAI in patients with intracranial aneurysm surgery (Table 3 ).

\section{Clinical outcomes}

This study included 542 cases of intracranial aneurysms and eight deaths in 2016; the mortality in the infection group was $4.7 \%$ and that of the control group was $1 \%$. The proportions with GOS score $\leq 3$ in the infection group and the control group were 70.3 and $9.6 \%$, respectively. The average hospitalization durations in the infection group and the control group were 19 days and 8 days respectively, and the difference was statistically significant $(P=0.000)$. The average hospitalization cost for the 64 infected patients was 205,853 Renminbi (RMB), while that for patients without hospital infection was 107,505 RMB. The medical expenses of the infection group were 1.9 times those of the control group. On

Table $1 \mathrm{HAl}$ site and composition ratio

\begin{tabular}{lll}
\hline Infection site & Infection cases & Composition ratio (\%) \\
\hline Respiratory system & 49 & 63.6 \\
Blood system & 16 & 20.8 \\
Central nervous system & 10 & 13.0 \\
Urinary system & 2 & 2.6 \\
Total & 77 & 100.0 \\
\hline
\end{tabular}

average, each infected case cost 98,348 RMB more than an uninfected one. The difference was statistically significant $(P=0.000)$. The average antibacterial drug fee for patients in the infection group was 1059 RMB, compared with $280 \mathrm{RMB}$ for patients without hospital infection; the difference was statistically significant (Table 4).

\section{Discussion}

\section{Current status of HAI}

HAI is a difficult issue and a key point in the clinical diagnosis and treatment of neurosurgery, especially in patients with severe neurosis; it is also an important factor affecting clinical treatment and patient prognosis [12]. Previous studies found that the incidence of HAI in non-Chinese neurosurgical hospitals was $6.7-11.1 \%[15,16]$, while the incidence in Chinese hospitals is 5.74-11.32\% [17-20]. In this study, the infection rate of patients with intracranial aneurysms was $11.8 \%$, and the infection case rate was $14.2 \%$. When compared with the overall infection rate of neurosurgery, the high infection rate may be related to the characteristics of the patients. Of the patients surveyed, $267(49.3 \%)$ were admitted to the ICU, 124 (22.9\%) were mechanically ventilated, and 530 (97.8\%) had indwelling artificial airways. Respiratory infections in hospital infections ranked first in this study (63.6\%), higher than the 2014 national hospital infection cross-sectional survey report [21] in which the incidence of respiratory infection was $47.53 \%$. The patients affected had impaired neurological function, multiple disturbances of consciousness, limited self-care ability, long periods of being bedridden, difficulty with sputum drainage, and invasive operation of the respiratory tract. In view of the preceding, prevention and treatment of respiratory infections should be the focus in neurosurgical hospitals, including shortening the time of surgical anaesthesia intubation and postoperative indwelling intubation, and focusing on turning over and draining. In this study, hospital infections occurred 1 to 18 days after surgery, with an average of 5 days after surgery. This is similar to the report by Laban [22] in which hospital infection after subarachnoid haemorrhage occurred in the first week after acute onset. It is suggested that the week following the operation is a high-risk period for hospital infection. This period should thus be considered crucial for the prevention and control of hospital infection.

\section{Risk factors for HAI}

Hospital infections in postoperative patients with intracranial aneurysms can be affected by a variety of factors. This study shows that patients admitted to hospital with GCS $\leq 8$ points, hyperglycaemia, hypothermia, and indwelling central venous catheterization are independent risk factors for nosocomial infection.

Patients with coma manifest disturbances of consciousness with inhibition of normal physiological reflexes such 
Table 2 Univariate analysis of $\mathrm{HAI}$

\begin{tabular}{|c|c|c|c|c|}
\hline Relevant factors & $\begin{array}{l}\text { Infection group } \\
(n=64)\end{array}$ & $\begin{array}{l}\text { Control group } \\
(n=478)\end{array}$ & $t / z / x^{2}$ & $P$ \\
\hline \multicolumn{5}{|l|}{ Gender n (\%) } \\
\hline Male & $31(48.4)$ & $194(40.6)$ & 1.433 & 0.231 \\
\hline Female & $33(51.6)$ & $284(59.4)$ & & \\
\hline \multicolumn{5}{|l|}{ Age n (\%) } \\
\hline$\leq 44$ years old & $8(12.5)$ & $79(16.5)$ & 2.737 & 0.255 \\
\hline $45-59$ years old & $28(43.8)$ & $239(50)$ & & \\
\hline$\geq 60$ years old & $28(43.8)$ & $160(33.5)$ & & \\
\hline Admission Activities of daily living $(A D L) M(Q)$ & $30(0-64)$ & $95(45-100)$ & -6.699 & 0.000 \\
\hline \multicolumn{5}{|l|}{ Admission route $\mathrm{n}(\%)$} \\
\hline Emergency & $47(73.4)$ & $191(40)$ & 25.687 & 0.000 \\
\hline Elective & $17(26.6)$ & $287(60)$ & & \\
\hline Hospitalization time $M(Q)$ & $19(15-24)$ & $8(6-12)$ & -10.295 & 0.000 \\
\hline \multicolumn{5}{|l|}{ Mechanical ventilation $n(\%)$} \\
\hline Yes & $48(75)$ & $76(15.9)$ & 111.735 & 0.000 \\
\hline No & $16(25)$ & 402(84.1) & & \\
\hline \multicolumn{5}{|l|}{ Hypertension n (\%) } \\
\hline Yes & $23(35.9)$ & $169(35.4)$ & 0.008 & 0.927 \\
\hline No & $41(64.1)$ & $309(64.6)$ & & \\
\hline \multicolumn{5}{|l|}{ Diabetes n (\%) } \\
\hline Yes & $9(14.1)$ & $69(14.4)$ & 0.006 & 0.936 \\
\hline No & $55(85.9)$ & $409(85.6)$ & & \\
\hline \multicolumn{5}{|l|}{ Coronary heart disease n (\%) } \\
\hline Yes & $5(7.8)$ & $19(4)$ & 1.964 & 0.161 \\
\hline No & $59(92.2)$ & $459(96)$ & & \\
\hline \multicolumn{5}{|l|}{ Immune system disease n (\%) } \\
\hline Yes & $1(1.6)$ & $7(1.5)$ & 0.004 & 0.952 \\
\hline No & $63(98.4)$ & $471(98.5)$ & & \\
\hline \multicolumn{5}{|l|}{ Steroids n (\%) } \\
\hline Yes & $12(18.8)$ & $115(24.1)$ & 0.887 & 0.346 \\
\hline No & $52(81.3)$ & $363(75.9)$ & & \\
\hline \multicolumn{5}{|l|}{ Antiplatelet aggregate n (\%) } \\
\hline Yes & $11(17.2)$ & $221(46.2)$ & 19.452 & 0.000 \\
\hline No & $53(82.8)$ & $257(53.8)$ & & \\
\hline \multicolumn{5}{|l|}{ Admission GCS score n (\%) } \\
\hline$\leq 8$ points & $25(39.1)$ & $19(4)$ & 93.161 & 0.000 \\
\hline$>8$ points & $39(60.9)$ & $459(96)$ & & \\
\hline \multicolumn{5}{|l|}{ Admission Hunt-Hess classification n (\%) } \\
\hline$\leq 2$ points & $35(54.7)$ & $435(91)$ & 64.623 & 0.000 \\
\hline$\geq 3$ points & $29(45.3)$ & $43(9)$ & & \\
\hline \multicolumn{5}{|l|}{ Leukopenia n (\%) } \\
\hline Yes & $2(3.1)$ & $19(4)$ & 0.109 & 0.741 \\
\hline No & $62(96.9)$ & $459(96)$ & & \\
\hline
\end{tabular}

Albumin reduction $\mathrm{n}(\%)$ 
Table 2 Univariate analysis of HAl (Continued)

\begin{tabular}{|c|c|c|c|c|}
\hline Relevant factors & $\begin{array}{l}\text { Infection group } \\
(n=64)\end{array}$ & $\begin{array}{l}\text { Control group } \\
(n=478)\end{array}$ & $t / z / x^{2}$ & $P$ \\
\hline Yes & $14(21.9)$ & $36(7.5)$ & 13.867 & 0.000 \\
\hline No & $50(78.1)$ & $442(92.5)$ & & \\
\hline \multicolumn{5}{|l|}{ Hyperglycaemia n (\%) } \\
\hline Yes & $45(70.3)$ & $166(34.7)$ & 30.062 & 0.000 \\
\hline No & $19(29.7)$ & $312(65.3)$ & & \\
\hline \multicolumn{5}{|c|}{ Abnormal liver function $\mathrm{n}(\%)$} \\
\hline Yes & $6(9.4)$ & $43(9)$ & 0.010 & 0.921 \\
\hline No & $58(90.6)$ & $435(91)$ & & \\
\hline \multicolumn{5}{|c|}{ Abnormal renal function $\mathrm{n}(\%)$} \\
\hline Yes & $3(4.7)$ & $5(1)$ & 2.947 & 0.086 \\
\hline No & $61(95.3)$ & $473(99)$ & & \\
\hline \multicolumn{5}{|l|}{ Hyperkalaemia n (\%) } \\
\hline Yes & $1(1.6)$ & $1(0.2)$ & 0.335 & 0.562 \\
\hline No & $63(98.4)$ & $477(98.8)$ & & \\
\hline \multicolumn{5}{|l|}{ Hypokalaemia n (\%) } \\
\hline Yes & $9(14.1)$ & $54(11.3)$ & 0.420 & 0.517 \\
\hline No & $55(85.9)$ & $424(88.7)$ & & \\
\hline \multicolumn{5}{|l|}{ Hypernatremia n (\%) } \\
\hline Yes & $3(4.7)$ & $14(2.9)$ & 0.142 & 0.707 \\
\hline No & $61(95.3)$ & $464(97.1)$ & & \\
\hline \multicolumn{5}{|l|}{ Hyponatremia n (\%) } \\
\hline Yes & $12(18.8)$ & $26(5.4)$ & 13.365 & 0.000 \\
\hline No & $52(81.3)$ & $452(94.6)$ & & \\
\hline \multicolumn{5}{|l|}{ Surgical approach n (\%) } \\
\hline Intervention & $22(34.4)$ & $320(66.9)$ & 25.716 & 0.000 \\
\hline Craniotomy & $42(65.6)$ & $158(33.1)$ & & \\
\hline \multicolumn{5}{|l|}{ Surgery duration n (\%) } \\
\hline$\leq 4 \mathrm{~h}$ & $30(46.9)$ & $365(76.4)$ & 24.825 & 0.000 \\
\hline$>4 h$ & $34(53.1)$ & $113(23.6)$ & & \\
\hline \multicolumn{5}{|l|}{ Non-class I incision n (\%) } \\
\hline Yes & $1(1.6)$ & $2(0.4)$ & 0.964 & 0.326 \\
\hline No & $63(98.4)$ & 476 (99.6) & & \\
\hline \multicolumn{5}{|l|}{ Surgical level n (\%) } \\
\hline Small & 0 & $1(0.2)$ & 6.914 & 0.075 \\
\hline Medium & $1(1.6)$ & $32(6.7)$ & & \\
\hline Large & $4(6.3)$ & $9(1.9)$ & & \\
\hline Extra large & $59(92.2)$ & $436(91.2)$ & & \\
\hline \multicolumn{5}{|c|}{ Anaesthesia method n (\%) } \\
\hline General anaesthesia & $64(100)$ & $465(97.3)$ & 0.811 & 0.368 \\
\hline Local anaesthesia & 0 & $13(2.7)$ & & \\
\hline \multicolumn{5}{|c|}{ Intraoperative blood loss n (\%) } \\
\hline$<1000 \mathrm{ml}$ & $60(93.8)$ & $473(99)$ & 6.445 & 0.011 \\
\hline$\geq 1000 \mathrm{ml}$ & $4(6.3)$ & $5(1)$ & & \\
\hline
\end{tabular}


Table 2 Univariate analysis of HAl (Continued)

\begin{tabular}{|c|c|c|c|c|}
\hline Relevant factors & $\begin{array}{l}\text { Infection group } \\
(n=64)\end{array}$ & $\begin{array}{l}\text { Control group } \\
(n=478)\end{array}$ & $t / z / x^{2}$ & $P$ \\
\hline \multicolumn{5}{|c|}{ Unexpected reoperation n (\%) } \\
\hline Yes & $8(12.5)$ & $8(1.7)$ & 19.468 & 0.000 \\
\hline No & $56(87.5)$ & $470(98.3)$ & & \\
\hline \multicolumn{5}{|c|}{ Hypothermia treatment n (\%) } \\
\hline Yes & $26(40.6)$ & $11(2.3)$ & 124.376 & 0.000 \\
\hline No & $38(59.4)$ & $467(97.7)$ & & \\
\hline \multicolumn{5}{|c|}{ Artificial airway n (\%) } \\
\hline Yes & $64(100)$ & $466(97.5)$ & 0.688 & 0.407 \\
\hline No & 0 & $12(2.5)$ & & \\
\hline \multicolumn{5}{|c|}{ Indwelling catheter n (\%) } \\
\hline Yes & $64(100)$ & $474(99.2)$ & 1.009 & 0.315 \\
\hline No & 0 & $4(0.8)$ & & \\
\hline \multicolumn{5}{|c|}{ Central venous catheter n (\%) } \\
\hline Yes & $58(90.6)$ & $119(24.9)$ & 110.883 & 0.000 \\
\hline No & $6(9.4)$ & $359(75.1)$ & & \\
\hline
\end{tabular}

as swallowing and coughing, resulting in increased respiratory tract secretions and susceptibility to bacterial reproduction. In addition, patients with coma tend to suffer from severe diseases, with the need for tracheal intubation, tracheotomy, mechanical ventilation, nasogastric stomach tube, or urinary tract intubation-assisted treatment. Such operations can damage the mucosa and decrease its barrier function; this is an important risk factor for nosocomial infection [13, 23]. Therefore, patients with coma should be actively treated and their early waking encouraged, as well as strictly controlling the indications for invasive operations, performing operations under strict aseptic conditions, promoting gentle movement, keeping the airway open, and ensuring the removal of deep sputum to reduce the incidence of infection.

Consistent with previous studies, the results indicate that hyperglycaemia is another risk factor for nosocomial HAI [24]. Hyperglycaemia increases plasma osmotic pressure of patients, inhibits the chemotaxis activity, adhesion ability, phagocytic ability and intracellular killing effect of leucocyte, and reduces the body's resistance to infection. In addition, long-term hyperglycaemia favours bacterial reproduction, especially in the respiratory tract, urinary tract, skin, and female patients' genital area, which increases the risk of infection [25]. Consequently, attention should be paid to the monitoring and management of blood sugar and control of glucose intake, as well as whether diabetic patients develop a further increase in blood sugar after trauma, or non-diabetic patients experience stress hyperglycaemia as a result of trauma, surgery, or other stress conditions [26].

Of the patients undergoing aneurysm surgery and admitted to our department in 2016, 37 patients were treated with hypothermia. Their targeted temperature range was $33-35^{\circ} \mathrm{C}$ and the continuous treatment time range was $1-10$ days. 26 out of 37 (70.3\%) had hospital infections. This incidence rate was significantly higher than that among non-hypothermia patients. In the infection group, 24 (64.9\%) of infection cases were respiratory infections and six (16.2\%) were bloodstream infections. Shiozaki et al [27] found that the incidence of respiratory infection in patients treated with hypothermia was $49 \%$, lower than that found in this study. Hypothermia treatment is a common therapeutic schedule for patients undergoing neurosurgery, especially those with severe craniocerebral injury, as it can reduce brain metabolism

Table 3 Multivariate analysis of HAI

\begin{tabular}{lllllll}
\hline Variable & $B$ & S.E. & Wald & $P$ & OR & $95 \%$ Cl \\
\hline Admission GCS score $\leq 8$ points & 1.450 & 0.690 & 4.414 & 0.036 & 4.261 & $1.102-16.476$ \\
Hyperglycaemia & 1.015 & 0.442 & 5.264 & 0.022 & 2.759 & $1.159-6.564$ \\
Hypothermia treatment & 1.881 & 0.547 & 11.816 & 0.001 & 6.557 & $2.244-19.159$ \\
Central venous catheter & 2.181 & 0.576 & 14.313 & 0.000 & 8.853 & $2.860-27.398$ \\
Constant & -4.001 & 1.753 & 5.209 & 0.022 & 0.018 & - \\
\hline
\end{tabular}


Table 4 Clinical outcomes

\begin{tabular}{llll}
\hline & $\begin{array}{l}\text { Infection group } \\
(n=64)\end{array}$ & $\begin{array}{l}\text { Control group } \\
(n=478)\end{array}$ & Statistics \\
\hline GOS score $\mathrm{n}(\%)$ & & $5(1.0)$ & 110.413 \\
$\quad$ Mortality; GOS $=1$ & $3(4.7)$ & $41(8.6)$ & 0.000 \\
Poor outcome; GOS $=2 / 3$ & $42(65.6)$ & $432(90.4)$ & -10.295 \\
Good outcome; GOS $=4 / 5$ & $19(29.7)$ & $8(6-12)$ & -7.381 \\
Hospitalization time (day) & $19(15-24)$ & $107,505(76,548-153,882)$ & 0.000 \\
Hospitalization cost (RMB) & $205,853(142,293-289,816)$ & $280(0-398)$ & 0.000 \\
Antibacterial drug fee (RMB) & $10,059(5,021-19,570)$ & & 0.000 \\
\hline
\end{tabular}

and thus limit brain damage. This is particularly important for patients with severe cerebral vasospasm and severe intracranial pressure, as it can reduce the gap between effective cerebral perfusion and the cerebral metabolic needs of brain blood flow [28]. On the other hand, hypothermia may lead to decreased systemic immune function. Patients treated with hypothermia treatment were accompanied by mechanical ventilation and sedative analgesic medication. The use of mechanical ventilation may lead to deep airway bacterial colonization in patients, and sedative analgesic medication may cause cough reflexes to be inhibited [29]. These may aggravate and/or lead to infection and other complications [30]. It has been suggested that for patients receiving hypothermia treatment, nursing staff should not only cooperate with doctors to carry out effective body temperature control for brain protection, but also pay attention to infection control, pipeline care, skin care, environmental monitoring, and respiratory management.

Patients undergoing neurosurgery tend to experience severe surgical trauma and rapid changes in condition; they are also bedridden for long periods. Due to the need for monitoring and treatment, central venous catheterization is widely used in clinical practice. In this study, 177 patients (32.7\%) had indwelling central venous catheters. Although central venous catheterization is a relatively mature and routine technique [31], such invasive procedures damage the tissue mucosa, destroying the body's normal defence barrier. This allows certain conditional pathogens to invade the patient's body, or ectopic implantation of the normal flora to take place. The probability of infection increases with the extension of catheter retention time [9]. The results of this study were consistent with previous reports in this regard; 58 patients $(32.8 \%)$ with catheterization had hospital infections, significantly more than the six (1.6\%) patients without catheterization. Therefore, daily assessment of the need for an indwelling central venous catheter and early removal of the catheter are significant tasks when it comes to prevention and control of hospital infections. During the indwelling of the central venous catheter, the nursing staff should perform maintenance of the catheter by strictly replacing the infusion and static push drugs; replacement of the catheter dressing is a delicate mandate and should be done by trained intravenous infusion nurses to prevent the occurrence of hospital infections.

This was a single-centre, retrospective study, although its results were confirmed by a multicentre prospective study. Furthermore, this study did not provide long-term follow-up of patients. The long-term impact of HAI on patients with intracranial aneurysms and their prognosis is not yet clear and needs to be further studied.

\section{Conclusions}

In summary, the incidence of hospital infections is higher in patients with intracranial aneurysms, it is especially the case of respiratory infections. Coma on admission, hyperglycaemia, hypothermia, and indwelling central venous catheterization are major risk factors for HAI in patients with intracranial aneurysms. Hospital infections affect a patient's prognosis, prolongs their hospitalization time, and increase their medical expenses. The amount of hospital infections could be reduced by training medical staff on infection and prevention, strengthening the monitoring and management of susceptibility factors and risk factors for high-risk patients with neurosurgical hospital infections, and actively taking corresponding preventive measures. Standardized diagnosis and treatment of patients with hospital infections, through multidisciplinary collaboration and the cooperation and support of relevant professionals, would promote early control of hospital infections and improve patients' prognosis and outcomes.

\section{Abbreviations}

ADL: Activities of daily living; CVC: Central venous catheterisation; GCS: Glasgow Coma Scale; GOS: Glasgow Outcome Scale; HAl: Hospitalacquired infection; ICU: Intensive care unit; RMB: Renminbi

\section{Acknowledgements}

We would like to thank the NICU nurses for contributing to data collection for this study.

\section{Authors' contributions}

JW and HQZ designed the study. YYL designed the data collection tool. LDJ and XZ selected patients. YYJ, PY and JY monitored data collection. SCG 
mainly analyzed data. YYJ drafted and revised the manuscript. All authors read and approved the final manuscript.

\section{Funding}

This study was supported by the National Key Research Project on Prevention and Control of Chronic Non-communicable Diseases of the Ministry of Science and Technology [grant number 2016YFC1300800]. The funding bodies had no role or interference in the design of the study, collection, analysis, interpretation of data and in writing the manuscript.

\section{Availability of data and materials}

The datasets obtained during this study are available from the corresponding author on reasonable request.

\section{Ethics approval and consent to participate}

All procedures performed in studies involving human participants were in accordance with the ethical standards of the institutional and/or national research committee and with the 1964 Helsinki declaration and its later amendments or comparable ethical standards. This study was approved by the Xuanwu Hospital Ethics Review Committee (Clinical Research Council [2017]024). For this type of study, formal consent is not required.

\section{Consent for publication}

Not applicable.

\section{Competing interests}

The authors declare that they have no competing interests.

\section{Author details}

${ }^{1}$ Department of Neurosurgery, Xuanwu Hospital, Capital Medical University, China International Neuroscience Institute (China-INI), 45 Changchun Street, Beijing 100053, China. ${ }^{2}$ Hospital Infection Management Division, Xuanwu Hospital, Capital Medical University, Beijing, China. ${ }^{3}$ Centre for Evidence-Based Medicine, Xuanwu Hospital, Capital Medical University, Beijing, China.

Received: 18 June 2019 Accepted: 11 December 2019 Published online: 20 December 2019

\section{References}

1. Wałaszek M. The analysis of the occurrence of nosocomial infections in the neurosurgical ward in the district hospital from 2003-2012. Przegl Epidemiol. 2015:69:507-14.

2. Singh M, Guth JC, Liotta E, Kosteva AR, Bauer RM, Prabhakaran S, Rosenberg $\mathrm{N}$, Bendok BR, Maas MB, Naidech AM. Predictors of 30-day readmission after subarachnoid hemorrhage. Neurocrit Care. 2013;19:306-10. https://doi.org/ 10.1007/s12028-013-9908-0

3. Deng M, Lin N. Nosocomial infection and related risk factors in neurosurgery: a clinical analysis. Chin J Nosocomiol. 2005;15:739-42.

4. World Health Organization. WHO Guidelines on hand hygiene in health care: first global patient safety challenge clean care is safer care. Geneva: WHO; 2009. Available on: http://apps.who.int/iris/bitstream/10665/44102/1/ 9789241597906_eng.pdf. Accessed 5 Feb 2019.

5. Umscheid CA, Mitchell MD, Doshi JA, Agarwal R, Williams K, Brennan PJ. Estimating the proportion of healthcare-associated infections that are reasonably preventable and the related mortality and costs. Infect Control Hosp Epidemiol. 2011;32:101-14. https://doi.org/10.1086/657912.

6. Savardekar A, Gyurmey T, Agarwal R, Podder S, Mohindra S, Gupta SK, Chhabra R. Incidence, risk factors, and outcome of postoperative pneumonia after microsurgical clipping of ruptured intracranial aneurysms. Surg Neurol Int. 2013;4:24. https://doi.org/10.4103/2152-7806.107894.

7. Frontera JA, Fernandez A, Schmidt JM, Claassen J, Wartenberg KE, Badjatia N, Parra A, Connolly ES, Mayer SA. Impact of nosocomial infectious complications after subarachnoid hemorrhage. Neurosurgery. 2008;62:80-7. https://doi.org/10.1227/01.NEU.0000311064.18368.EA

8. Cinotti R, Dordonnat-Moynard A, Feuillet F, Roquilly A, Rondeau N, Lepelletier D, Caillon J, Asseray N, Blanloeil Y, Rozec B, Asehnoune K. Risk factors and pathogens involved in early ventilator-acquired pneumonia in patients with severe subarachnoid hemorrhage. Eur J Clin Microbiol Infect Dis. 2014;33:823-30. https://doi.org/10.1007/s10096-013-2020-8.
9. Kaya H, Turan Y, Akbal S, Tosun K, Aksoy E, Tunalı Y, Özdemir AG. The effect of nursing care protocol on the prevention of central venous catheter-related infections in neurosurgery intensive care unit. Appl Nurs Res. 2016;32:257-61. https://doi.org/10.1016/j.apnr.2016.08.006.

10. Tvedt C, Sjetne IS, Helgeland J, Løwer HL, Bukholm G. Nurses' reports of staffing adequacy and surgical site infections: a cross-sectional multi-Centre study. Int J Nurs Stud. 2017;75:58-64. https://doi.org/10.1016/j.jpurstu.2017.07.008.

11. Hill C. Nurse-led implementation of a ventilator-associated pneumonia care bundle in a children's critical care unit. Nurs Child Young People. 2016;28:23-7. https://doi.org/10.7748/ncyp.28.4.23.s21.

12. Society of Neurosurgery of Chinese Medical Association. Expert consensus on infection diagnosis and treatment of severe neurosurgery patients in China (2017). Natl Med J China. 2017:97:1607-14.

13. Li Y, Zeng P. Risk factors for nosocomial infections in neurosurgery department patients and prevention measure. Chin J Nosocomiol. 2013:23:5714-5.

14. Minstry of Health of the People's Republic of China. Diagnostic criteria for nosocomial infections (proposed). Natl Med J China. 2001;81:314-20.

15. Agarwal R, Mohapatra S, Rath GP, Kapil A. Active surveillance of health care associated infections in neurosurgical patients. J Clin Diagn Res. 2017;11:DC01-4. https://doi.org/10.7860/JCDR/2017/26681.10146.

16. Hopmans TEM, Blok HEM, Troelstra A, Bonten MJ. Prevalence of hospital-acquired infections during successive surveillance surveys conducted at a university hospital in the Netherlands. Infect Control Hosp Epidemiol. 2007;28:459-65.

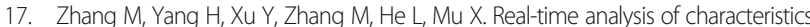
of nosocomial infections in neurosurgery department patients by information technology. Chin J Nosocomiol. 2016;18:4259-61.

18. Zhang JX, Hao J, Gao FM, Ma XQ. Risk factors of hospital infection in neurosurgery department. Chin J Nosocomiol. 2010;2019:2939-40.

19. Wei $C B$, Wang $H$. Analysis of risk factors for nosocomial infection in neurosurgical patients in a hospital. Clinical Research and Practice. 2016:22:106.

20. Wang YH. Risk factor analysis of hospital infection in neurosurgery department. Chin J Nosocomiol. 2008;18:1088-90.

21. Ren N, Wen XM, Wu A. Nation wide cross-sectional survey on healthcareassociated infection in 2014. Chin J Infect Control. 2016;15:83-7.

22. Laban KG, Rinkel GJ, Vergouwen MD. Nosocomial infections after aneurysmal subarachnoid hemorrhage: time course and causative pathogens. Int I Stroke. 2015:10:763-6. https:/doi.org/10.1111/ijs.12494

23. Ji XT, Zhao JB, Ma XE, Xue JF. Causes and preventive measures of neurosurgical infection. Chin J Neurosurg Dis Res. 2014;13:352-3.

24. Diringer MN, Bleck TP, Hemphill JC, Menon D, Shutter L, Vespa P, Bruder N, Connolly ES, Citerio G, Gress D, Hänggi D, Hoh BL, Lanzino G, Le Roux P, Rabinstein A, Schmutzhard E, Stocchetti N, Suarez Jl, Treggiari M, Tseng MY, Vergouwen MD, Wolf S, Zipfel GJ. Critical care management of patients following aneurysmal subarachnoid hemorrhage: recommendations from the Neurocritical care Society's multidisciplinary consensus conference. Neurocrit Care. 2011;15: 211-40. https://doi.org/10.1007/s12028-011-9605-9.

25. Sun L, Chen L. Mechanism of diabetes complicated by infection. Shandong Med. 2004:44:57.

26. Cheng S. Progress in diagnosis and treatment of post-traumatic stress hyperglycemia. Chongqing Med. 2012:41:3543-5.

27. Shiozakki T, Hayakata T, Taneda M, Nakajima Y, Hashiguchi N, Fujimi S, Nakamori $Y$, Tanaka H, Shimazu T, Sugimoto H. A multicenter prospective randomized controlled trail of the efficacy of mild hypothermia for severely head injured patients with low intracranial pressure. Mild Hypothermia Study Group in Japan. J Neurosurg. 2001;94:50-4.

28. Seule MA, Muroi C, Mink S, Yonekawa Y, Keller E. Therapeutic hypothermia in patients with aneurysmal subarachnoid hemorrhage, refractory intracranial hypertension, or cerebral vasospasm. Neurosurgery. 2009;64:86-92. https:/doi.org/ 10.1227/01.NEU.0000336312.32773.A0.

29. Liu M, Wang ES. Therapeutic hypothermia and infection: recent progress. Chin J Clin Med. 2017;24:820-3. https://doi.org/10.12025/j.issn.1008-6358.2017.20170118.

30. Sun YR, Hu J, Zhou LF. Research progress of cryotherapy on brain protection. Chin J Neurosurg. 2016:32:1182-5.

31. Fang $\mathrm{X}$, Jin LD, Zhao JH. Characteristics and risk factors for nosocomial infections in 841 patients in department of neurosurgery. Chin J Nosocomiol. 2012;22:4240-2.

\section{Publisher's Note}

Springer Nature remains neutral with regard to jurisdictional claims in published maps and institutional affiliations. 